(2) Open Access Full Text Article

REVIEW

\title{
Impact of COVID-19 Pandemic on Post-Graduate Medical Education and Training in India: Lessons Learned and Opportunities Offered
}

\author{
Amit Patil (iD \\ Ranvir Ranjan \\ Prabhat Kumar \\ Himanshi Narang (D \\ Department of Forensic Medicine and \\ Toxicology, All India Institute of Medical \\ Sciences, Patna, Bihar, 80I507, India
}

Correspondence: Amit Patil

Department of Forensic Medicine and Toxicology, Second Floor, Academic

Building, All India Institute of Medical

Sciences, Phulwarisharif, Patna, Bihar,

80I507, India

Tel + (+9l) 9920193750

Email dramp1976@gmail.com

\begin{abstract}
Hands-on or practice-based learning is the foundational objective of postgraduate teaching and training. A skilled and competent postgraduate resident is critical to the country's health needs and is more relevant in the ongoing COVID-19 pandemic. The postgraduate medical training in India is speciality-specific and based on a structured curriculum and syllabus to achieve precise educational goals and objectives. The impact of this pandemic on postgraduate medical education and training is controversial, challenging, unknown, and far-reaching. The exceptional contagious nature of the virus and country-wide lockdowns have tremendously decreased hospital visiting patients. Abolition of outpatient and inpatient services, disruptions in clinical postings, curtailment of elective operations and procedures have adversely affected the training of residents and fellowship students in India and abroad. Apart from this, research work, mentoring, academic conferences, and workshops that offer learning experiences to these residents have been cancelled or suspended, thus denying them a chance to achieve domain knowledge and enhance their skills. Although this pandemic has offered new learning modes like teleconsultation, videoconferencing, virtual simulations, digital podcasts, etc., how much actual knowledge transfer and skill gain will be achieved is unanswered. Despite this disruption, this pandemic has offered a golden opportunity to relook at the current PG resident education and training programme. The lessons learned from this adversity offer medical universities, medical educators, and regulatory authorities many opportunities to develop a novel and innovative curriculum that enables the current and future residents to achieve the necessary proficiency and competency.
\end{abstract}

Keywords: COVID-19 pandemic, postgraduate, residents, medical education, training

\section{Introduction}

Hands-on learning is the foundation of the education of postgraduate residents (PGs). ${ }^{1}$ The medical education system is accountable for making a workforce of doctors who will help their citizens. ${ }^{2}$ Postgraduate residents form an indomitable force vital to any country's healthcare system. Global evidence on controlling mass casualty incidents have identified medical students as cornerstone in first-line care in pandemic planning and expect every physician and senior medical student to assist in disaster situations. ${ }^{3}$ During the postgraduate (PG) phase of medical education, the significant composition and skill set of residents, are developed. ${ }^{4}$

The World Health Organization (WHO) defines the social accountability of medical schools as 
the obligation to direct their education, research and service activities towards addressing the priority health concerns of the community, region, and nation they serve. ${ }^{5}$

This pandemic has triggered exceptional interruption in the medical education practice and the overall healthcare system. ${ }^{6}$ The current pandemic has seriously affected the postgraduate medical teaching and training course. The unprecedented lockdowns and fear of getting infection have reduced the number of patients attending hospitals. These events have ensued in a severe decline in the "clinical material and patient footfall," affecting PG students' training and clinical experience. ${ }^{7}$ The PG training programs are designed to develop specialists who can provide specific and evidence-based quality health care in their specialism. The PG resident training in India is broadly based on a defined speciality-based structured curriculum and syllabus, usually including clinical postings, rotations in other specialities, dissertation work, intensive care and emergency duties, etc. Disruption in the training period, many PGs risk losing extensive tenure of their academic course, leading to insufficient practical experience, ill training and inability to do dissertation research work. ${ }^{7}$ This is worrisome now as India grapples with the most severe and fatal second wave of COVID 19 infection.

The critical decision regarding PGs training like suspension of classes, cancellation of clinical rotatory postings, postponement of examinations and suspension of emergency services in India was made promptly due to the rapid development of the pandemic, without significant input from PGs themselves. ${ }^{8}$ The fast contagious nature of the virus has affected the lecture delivery process, thus dwindling the education process, which is principally lecture and patient-based learning. ${ }^{9,10}$ The postgraduate students pursuing training are more affected and stressed as they have to perform a dual part as PG trainee and frontline healthcare worker. PG trainees are the primary workforce to deal with a massive influx of COVID-19 patients. Working in high-demand departments like COVID intensive care units, cancellation of teaching programmes, and study leaves, uncertainty regarding jobs is likely to adversely impact their mental and physical wellbeing. ${ }^{11,12}$ The question here is whether PG residents can grow as qualified and competent clinicians due to the gaps created in their training. ${ }^{13}$

This review article attempts to understand the consequence of the COVID-19 pandemic on postgraduate training, highlighting its impact on PG students. Through their institutional administrative work related to PG residents, the authors have identified the lacunae in the PG resident training in the COVID-19 pandemic. Further, informal interviews and feedback from the doctors and PG students at the author's institute have highlighted this gap created in their training. The adverse pandemic may also have a silver lining of the opportunity to reframe and revise the existing rigid training structure and curriculum, emphasizing developing newer teaching and learning methods to address PG students' needs and goals.

\section{Impact on Structured Curriculum and Core Values of Postgraduate Training Programs}

Postgraduate programs in medical sciences are intended to develop clinicians and researchers and typically incorporate residencies, super-speciality residency, and fellowships. ${ }^{14}$ The medical education system follows a well-structured curriculum in a diverse preclinical and clinical setting whose objectives and conditions are set. ${ }^{15}$ Postgraduate training programs have specific inherent central values, including clinical training, research, mentoring and teaching. The postgraduate program offered by various Indian Medical Schools and Universities usually follows a uniform training pattern with few exclusions that depend on the subject speciality. It includes speciality postings, rotations in other specialities, case and seminar presentations, and dissertation/research work. The PGs are involved in outpatient and inpatient management during duty hours. They are also required to attend emergency duties that include managing acute emergency care and emergency operations. However, the COVID-19 pandemic has severely affected almost all training domains and values.

\section{Teaching \& Mentoring}

As a core value, teaching impacts all aspects of postgraduate training, regardless of whether it is the education of the postgraduate students, fellows, and the residents or their responsibilities to teach other individuals. Postgraduate teaching has suffered critically with the blockage of conventional methods as lectures, clinical rounds, academic meetings, seminar and case presentations, clinical grand rounds and other academic activities. ${ }^{16}$ Mentoring is a common denominator in all postgraduate training programs. During clinical rounds, the interplay between the guides and his residents is 
greatly affected in this crisis, affecting bedside teaching, inadequate mentoring of PGs and lack of personal and practical experience and knowledge. The resident training structure offered in India is so versatile across different institutes that it suffers from several limitations and additional challenges like lack of doctors, fewer patients, absence of hospital infrastructure, and absence of regulatory approvals. Most of them cannot provide comprehensive training and make sound specialists at the end of the PG course. This sickness has further intensified these issues. ${ }^{17}$ Online survey on the impact of COVID-19 on PG Orthopaedic training in India has reported cancellation of seminars, journal clubs and interdepartmental academic meets. $65.8 \%$ of respondents claimed that no clinical classes were conducted. ${ }^{18}$

High patient footfalls are necessary to enhance medical trainee education who observe unusual presentations of common and rare diseases. The residents training program requires a trainee to perform a minimum number of procedures or operations as a part of their training. But the pandemic situation entailed them abandoning these criteria, impacting their proficiency in such therapeutic or diagnostic procedures. Nevertheless, change in speciality and relocation of residents in departments with greater demand like ICU disrupts residency education plans and may suffer issues with board requirements. ${ }^{13}$

\section{Dissertations \& Research}

Residency programs and most fellowships require their residents to conduct research and present it in a dissertation or thesis, a prerequisite for completing the academic course. During the pandemic, most of the "benchtop" and "wet-lab" research was promptly halted, and most postgraduate students were altered to elective exercises that were admissible and executable The pandemic also placed a hold on patients' dynamic enrollment into clinical trials; nonetheless, select protocols continued to be conducted remotely (eg, e-consent, virtual appointments). Some learners were offered a chance to be redeployed to research endeavours zeroing in on COVID-19. Dissertations are mandatory for a resident academic course and residents to comprehend and embrace this research work, laying the groundwork for more research and publications in the future. The outcome of dissertation research work helps in advancing medical knowledge and serves the health needs of the present and future patients. PG students who have a dissertation to submit are in difficult situations due to non-follow-up of enrolled patients and difficulty recruiting new patients for the study. ${ }^{18}$ Unfortunately, the PGs in the current pandemic could not perform high-quality research due to the scarcity of clinical material, reduced patient load, absence of guide supervision, mental stress and other work like COVID-19 duties. ${ }^{19}$ The fate of dissertations hangs in limbo in the lack of adequate clinical material to carry out the thesis research work.

\section{Academic Conferences \& Workshops}

Academic conferences allow residents to share their research findings and improve their experience via paper or poster presentations. These openings may excel the professional career of residents who seek further advanced training in competitive subspecialties. It is desirable as a part of the curriculum for PG students to present a poster at a conference and at least attend two conference or workshops. ${ }^{18}$ Many of these conferences and workshops have chosen to replace the regular in-person gettogethers with a virtual online platform to deliver educational content. Though residents can present their study findings online, residents miss the occasion of connecting their subject or field experts. Such interacting opportunities are easier to gain during face-to-face acquaintances. ${ }^{20}$

\section{Clinical Practice}

As outpatient volume reduced drastically in this pandemic with the cancellation of non-urgent and non-COVID clinic appointments, most of these consultations happened over the cell phone or through video calls on intelligent mobile phones. Such teleconsultation does not include the traditional physical examination method of touching the patient, which is an essential skill that can be mastered mostly during residency training. Reduced non-covid patient services, both outpatient and inpatient, severely mitigated the opportunities for trainee residents to perform essential procedures. As reported, before the COVID era, residents were likely to see a broad spectrum of cases varying from routine uncomplicated to life-threatening severe cases; however, their focus is now shifted to COVID-19. ${ }^{4}$

Though online learning offers diversity and educational value, the absence of bedside teaching forfeits students' direct involvement and interaction with patients. The absence of bedside teaching hampered their development of physical examination skills and several other soft skills. The lack of feedback about students active engagement 
through direct observation and supervised learning has affected their in-person clinical assessment. ${ }^{4}$ The increased workload and responsibility in COVID-19 specific areas threatened educational and training aspects of residency.

Given the pandemic, the amount of patient interactions that PGs make out has significantly reduced. As many patients clinical activities have been shifted to virtual mode, few actions have been suspended inconclusively. Conversely, new opportunities have unfurled, like teleconsultation, where residents are conducting follow-up appointments. Loss of in-person interaction with patients and their teachers may keep PG students from gaining confidence, building up their practice style, and getting ready for independent practice. Since the main focus is COVID-19 patients, the limited number of non-covid patients and restricted hospital care services, the bedside teaching opportunities for PGs is hampered. ${ }^{21}$ Earlier study conducted has reported that almost all the PG trainees felt a lack of clinical teaching on the ward rounds and case presentations. ${ }^{18}$ Few regional studies have expressed that the medical students did not find online classes as effective as traditional classroom teachings and proposed face-to-face teaching that is more interactive and productive. The students and teachers are unsatisfied with the digital methodology of teaching, which will hamper the quality of education. $^{22,23}$

Amidst crisis, the clinical and research core values have been challenging to conserve, and, indeed, a considerable of them have come further into focus. In any case, the ability to prioritize teaching within this setting can be troublesome. A contention exists between the desire to give a once-in-a-lifetime teaching experience and the craving to keep residents or fellows safe in the health care environment. In the aftermath of this pandemic, educators should identify which parts of the traditional teaching and learnings need to be retained in the medical curriculum and what features can be switched to virtual learning models.

\section{Effect of COVID- 9 Pandemic on Medical Education and Clinical Training}

It is true to say that all facets of health education and clinical training are harshly affected by the pandemic. There is no denying that clinical postings, rotatory ship, electives, and internships are suspended in this crisis. Since clinical training and didactic lectures were considered unsafe due to physical distancing, online modalities suddenly replaced the traditional teaching-learning methods.

The risk of trainees exposure to viral infection made many hospitals change their clinical posting and training policies. In addition, the transfer of residents to COVIDrelated services has affected the staffing pattern in other critical service areas of the hospital, such as the Intensive Care Unit (ICU), emergency medicine, operation theatres etc.

The clinical training in surgical specialities has been profoundly affected mainly due to two reasons. Firstly, the surgical residents were shifted to do COVID related clinical work in ICU and dedicated COVID wards. Secondly, postponement of elective surgeries and allowing urgent or emergency surgeries, thus denying them of learning opportunities. The electives are what the surgery residents usually perform independently or with minimal supervision in more complex life-threatening operations. Further, restricting the number of personnel in the operating rooms as a policy matter during this COVID-19 pandemic reduced their learning opportunities by observing the operative procedures. ${ }^{24}$

\section{Inadequate Training and Possible Therapeutic/Diagnostic Errors}

The art of diagnosis with reasoning skills required utmost precision, which PGs master in residency programs. Doubt regarding resumption of clinics, procedures, exhaustive clinical postings in critical areas, and loss of psychomotor training skills have led to residents developing blunt clinical reasoning skills. Apart from internal determinants such as motivation, burnout etc., external factors can also influence the process of clinical reasoning, such as time constraints, environmental cues, and lack of investigations. $^{25}$

Restraint on diagnostic reasoning due to the absence of physical examination of the patient done with physical distancing has stressed more upon unwanted investigations. ${ }^{26}$ The residents unduly jumping on to diagnosis or hesitantly misdiagnosing patients' clinical condition without thoroughly evaluating them has cast a considerable shadow on their reasoning process. Patients may often be subjected to unwarranted computed tomography scans or laboratory investigations to clear the air of suspicious COVID viral infection. The continuous deluge of COVID-related information and constantly changing protocol have blurred 
residents' intellect to concentrate upon other associated information, leading to diagnostic errors. ${ }^{27}$

\section{Adverse Health of Residents}

The PGs posted for COVID-19 duties are exposed to mental stress and possibly a high possibility of acquiring the viral infection. COVID-19 infection is supposed to affect the mental health of the public and that of healthcare professionals. ${ }^{28-31}$ Researchers saw significant anxiety in the faculty and students who were given additional duties in the pandemic. ${ }^{32}$ The ongoing pandemic has added new stressors while aggravating the existing ones for students. The expected academic loss with disturbed traditional learning processes and yet to be achieved academic milestones have contributed to the students' anxiety about wellness stressors. ${ }^{33}$

Witnessing a patient's death is not new to medicine or anaesthetic resident in an Intensive Care Unit (ICU). The sheer volume of deaths observed during this COVID-19 pandemic by a trainee resident during their COVID duties may itself have a catastrophic effect on their mental health. No resident is prepared or trained to handle or visualize such a devastating situation, especially when such deaths happen suddenly and mainly due to lack of medicines, ventilator, ICU beds. Regretfully incapacitated to avoid them, these residents are mute spectators to all these events and probably may repent of the futile and ineffective efforts to minimize or elude such deaths.

The support arrangements for medical learners need to widen these possibilities to acknowledge the development of additional stress related to the pandemic work in an already stressful and challenging training environment. Wellness measures, recreation facilities and psychiatric counselling must be made available to reduce posttraumatic stress disorders of the students.

\section{Moving Forward: The Implication for Policy and Practice}

The system of education and training in medicine is complex. The physician's early mindset that the physician will work sick was considered courteous and professional, prioritizing the patient above the physician. Adjustments in the training structure to respond to this pandemic have opened new teaching and training methods. Electronic learning, video calls, and online examinations are a few of the newer technologies in education and learning, which will probably remain long. ${ }^{34}$
Online discussions of cases is an intended solution in such a difficult time of learning. Initially, the students are allotted a clinical case for studying. A week later, they make online case presentation of patients illness, symptomatology, examination findings, interpretation of findings, proposed investigations and treatment plans. During the case discussion with a teaching physician, the learner can ask question utilizing this virtual stage. Such a visual interface will mimic bedside teaching. ${ }^{35,36}$

The role of teleconsultation was undermined in the preCOVID era. But in the current pandemic situation, telemedicine and teleconsultation have offered solutions to overcome the difficulties of medical education. Patient examination and consultation did virtually under the supervision of a faculty may give insightful training to residents and assist them in obtaining clinical experience by collaborating with genuine patients. ${ }^{6}$ It would be valuable if clinicians had the chance to treat people with severe and chronic conditions through virtual clinical consultation, thus minimizing the risk of infection and responsibility of doctors in this outbreak. ${ }^{37}$

A significant challenge for residents in the current pandemic situation is to duplicate the experience of clinical exposure. These exposures vary from OPD and ward postings, where they have interactive correspondence with patients and faculty during case presentation sessions, thus helping in clinical and communication skills enhancement. Electronic learning platforms like video conferencing, digital podcasts, online classroom teaching, and virtual simulations are helping teachers and facilitating student learning and training in specific domains. Today, online platforms, such as websites and blogs, can give fundamental data yet, in addition, extend the chance to host videos for exhibiting basic skills, such as procedural clinical skills and communication. ${ }^{38}$

Despite new modalities of innovative learning, some elements of the curriculum cannot be changed. ${ }^{15}$ The proposed new and innovative learning strategies should find their mention in the structured curriculum of postgraduate subjects or disciplines, including educational goals and objectives, assessment methods, and processes to guarantee that the defined learning goals are met.

\section{Hidden Learning Opportunities}

A crisis like this pandemic may offer some green shoots of opportunity to relook at the current PG medical training structure and possibly rigid curriculum. An excellent medical curriculum is dynamic, providing flexibility in 
teaching and learning and modifying it as and when required. Medical Schools/Universities and Medical educators may take this chance and plan a more vibrant and inclusive medical training structure to help these students achieve proficiency and competency in clinical skills in such a crisis.

Newer learning modalities like webcasts, podcasts, and videoconferencing can deliver lectures or tutorials via e-learning platforms using smartphones and laptops. Similarly, training programs can include teleconferencing, webinars, and online videos, while faculty may participate in online discussions, strengthening their learning.

This pandemic has taught us the most to have a holistic approach towards patient care for the best outcome. Though subject-specific knowledge and skill are essential other holistic non-cognitive attributes such as teamwork, empathy, courage, and compassion are essentials of clinical management to every medical student and resident. Unfortunately, this learning happens as part of a hidden curriculum.

The pandemic crisis has put forth medical residents at the forefront in the direction of COVID patients. Taking charge of the patients and their caregivers, handling the hospital settings' adverse situation, and steering these problems to amicable and peaceful solutions may help residents develop their leadership and managerial skills. Many authors have highlighted the importance of such hidden learning as a part of the informal curriculum. ${ }^{39-42}$ It greatly affects the growth of the professional identity of trainees $^{43-46}$ and can bode well for their development as medical professionals.

The mutating virus has made this pandemic versatile and volatile, as seen in the first and second waves of COVID infection, where symptomatology and treatment protocols change daily. These conditions offer versatility lessons as residents learn to adapt to ever-changing plans as the situation evolves. Also, such learning hone residents' skillsets about system-based practice, protocol-based organizational management, and limited resource optimization. ${ }^{47}$

\section{Conclusion}

The current pandemic is a new challenge for medical residents education and training. The short-term impact of the pandemic on postgraduate medical education and training is quite known; however, the long-term effect on the educational lacunas of residents remains unknown. However, the lessons and priorities learned throughout the COVID-19 pandemic have given us the opportunities to consider these long-term needs.
The pandemic has revealed that medical institutions and universities globally will need to adopt flexible, creative and responsive training strategies to educate this next generation of doctors. ${ }^{48}$ Residents and fellows working in a hospital have a dual role of hospital employee and postgraduate trainee. As patient care and clinical work are essential, similarly, the educational need and experience of the trainees are also of paramount importance.

Despite this disruption, this pandemic has offered a golden opportunity to relook at the current PG resident education and training programme. The lessons learned from this adversity offer medical universities, medical educators, and regulatory authorities to develop a novel and innovative curriculum that enables the current and future residents to achieve necessary proficiency and competency. Furthermore, further research should be done in the coming years to corroborate the current impact of the COVID-19 pandemic on resident training and skill development.

\section{Consent for Publication}

Yes.

\section{Author Contributions}

- The authors have contributed to the work reported, whether in the conception, study design, execution, data acquisition, analysis, and interpretation. They took part in drafting, revising and critically reviewing the article; and gave the final approval of this version to be published. The authors have agreed on the journal to which the article has been submitted and also agree to be accountable for all aspects of the work.

- All authors have read and approved the manuscript.

\section{Disclosure}

The authors report no conflicts of interest in this work.

\section{References}

1. Dornan T, Pearson E, Carson P, Helmich E, Bundy C. Emotions and identity in the figured world of becoming a doctor. Med Educ. 2015;49 (2):174-185. doi:10.1111/medu.12587

2. World Health Organization. A universal truth: no health without a workforce. Third global forum on human resources for a health report. World Health Organization; 2013 [cited April 28, 2021]. Available from: www.who.int/workforce.alliance/knowledge/ resources/hrhreport2013/en/. Accessed July 15, 2021.

3. Mortelmans LJM, Bouman SJM, Gaakeer MI, Dieltiens G, Anseeuw K, Sabbe MB. Dutch senior medical students and disaster medicine: a national survey. Int J Emerg Med. 2015;8(1):. doi:10.1186/ s12245-015-0077-0 
4. Philibert I, Blouin D. Responsiveness to societal needs in postgraduate medical education: the role of accreditation. BMC Med Educ. 2020;20(S1):309. doi:10.1186/s12909-020-02125-1

5. Boelen C, Heck J. Defining and Measuring the Social Accountability of Medical Schools. Geneva:Division of development of human resources for health, World Health Organization;1995:3. WHO/ HRH/95.7. Available from. http://whqlibdoc.who.int/hq/1995/WHO HRH_95.7.pdf. Accessed July 15, 2021.

6. Woolliscroft JO. Innovation in response to the COVID-19 pandemic crisis. Acad Med. 2020;95(8):1140-1142. doi:10.1097/ ACM.0000000000003402

7. Vaishya R. Plights of medical postgraduate students during COVID-19 pandemic. J Postgrad Med Educ Res. 2021;54 (3):158-159. doi:10.5005/jp-journals-10028-1399

8. Harries AJ, Lee C, Jones L, et al. Effects of the COVID-19 pandemic on medical students: a multicenter quantitative study. BMC Med Educ. 2021;21(1):14. doi:10.1186/s12909-020-02462-1

9. Sklar DP. COVID-19: lessons from the disaster that can improve health professions education. Acad Med. 2020;95(11):1631-1633. doi:10.1097/ACM.0000000000003547

10. Hopman J, Allegranzi B, Mehtar S. Managing COVID-19 in lowand middle-income countries. JAMA. 2020;323(16):1549-1550. doi:10.1001/jama.2020.4169

11. Scott R, Health R, Lostis E. COVID-19: junior doctors are worried about their physical and mental health. BMJ. 2020. Available form: https://blogs.bmj.com/bmj/2020/04/03/covid-19-juniordoctors-areworried-about-their-physical-and-mental-health. Accessed on July 15,2021

12. Rana W, Mukhtar S, Mukhtar S. Mental health of medical workers in Pakistan during the pandemic COVID-19 outbreak. Asian J Psychiatr. 2020;51:102080. doi:10.1016/j.ajp.2020.102080

13. Dedeilia A, Sotiropoulos MG, Hanrahan JG, Janga D, Dedeilias P, Sideris M. Medical and surgical education challenges and innovations in the COVID-19 era: a Systematic Review. In Vivo. 2020;34(3 suppl):1603-1611. doi:10.21873/invivo.11950

14. Persky AM, Fuller KA, Jarstfer M, Rao K, Rodgers JE, Smith M. The COVID-19 Pandemic Across The Academy. Am J Pharm Educ. 2020; 8(6).

15. Wayne DB, Green M, Neilson EG. Medical education in the time of COVID-19. Sci Adv. 2020;6(31):eabc7110. doi:10.1126/sciadv. abc7110

16. Lal H, Sharma D, Pratalesh M. Outpatient department practices in orthopaedics amidst COVID-19: the evolving model. J Clin Orthop Trauma. 2020;11(4):700-712. doi:10.1016/j.jcot.2020.05.009

17. Dougherty P, Jain A. Orthopaedic surgery education in India. Clin Orthop Relat Res. 2014;472(2):410-414. doi:10.1007/s11999-0133391-y

18. Upa GK, Jain VK, Iyengar K, Patralekh MK, Vais A. Impact of COVID-19 on post-graduate orthopaedic training in Delhi-NCR. $J$ Clin Orthop Trauma. 2020;11:S687-S695. doi:10.1016/j. jcot.2020.07.018

19. Dwivedi R, Kumar R. Postgraduate training requires urgent reforms to deal with future pandemics. J R Coll Physicians Edinb. 2020;50 (4):360-361. doi:10.4997/JRCPE.2020.402

20. Edigin E, Eaton PO, Shaka H, Ojemolon PE, Asemota IR, Akuna E. Impact of COVID-19 pandemic on medical postgraduate training in the United States. Med Educ Online. 2021;25(1):1774318

21. Calhoun KE, Yale LA, Whipple ME, Allen SM, Wood DE, Tatum RP. The impact of COVID-19 on medical student surgical education: implementing extreme pandemic response measures in a widely distributed surgical clerkship experience. Am J Surg. 2020;220(1):44-47. doi:10.1016/j.amjsurg.2020.04.024

22. Sigdel S, Ozaki A, Dhakal R, Pradhan B, Tanimoto T. Medical education in Nepal: impact and challenges of the COVID-19 pandemic. Acad Med. 2021;96(3):340-342. doi:10.1097/ ACM.0000000000003888
23. Nepal S, Atreya A, Menezes RG, Joshi RR. Students' perspective on online medical education amidst the COVID-19 pandemic in Nepal. J Nepal Health Res Counc. 2020;18(3):551-555. doi:10.33314/jnhrc. v18i3.2851

24. Coccolini F, Perrone G, Chiarugi Met al. Surgery in COVID-19 patients: operational directives. World J Emerg Surg. 2020;15 (25):2-7.

25. Young M, Thomas A, Gordon D, et al. The terminology of clinical reasoning in health professions education: implications and considerations. Med Teach. 2019;41(11):1277-1284. doi:10.1080/ 0142159X.2019.1635686

26. Shuriya Prabha M, Dinesh Kumar V. What is lost in postgraduate residency during COVID-19 times? - a resident perspective on diagnostic error. Med Sci Educ. 2020;30(4):1339-1340. doi:10.1007/ s40670-020-01070-4

27. Sia C-H, Tan BY-Q, Ooi SBS. Impact of the coronavirus disease 2019 pandemic on postgraduate medical education in a Singaporean academic medical institution. Korean $J$ Med Educ. 2020;32 (2):97-100. doi:10.3946/kjme.2020.157

28. Shaukat N, Ali DM, Razzak J. Physical and mental health impacts of COVID-19 on healthcare workers: a scoping review. Int $J$ Emerg Med. 2020;13(1):40. doi:10.1186/s12245-020-00299-5

29. Salari N, Khazaie H, Hosseinian-Far A, et al. The prevalence of stress, anxiety and depression within front-line healthcare workers caring for COVID-19 patients: a systematic review and meta-regression. Hum Resour Health. 2020;18(1):100. doi:10.1186/ s12960-020-00544-1

30. Lasalvia A, Bonetto C, Porru S, et al. Psychological impact of COVID-19 pandemic on healthcare workers in a highly burdened area of north-east Italy. Epidemiol Psychiatr Sci. 2020;30:e1. doi:10.1017/S2045796020001158

31. Sunil R, Bhatt MT, Bhumika TV, et al. Weathering the storm: psychological impact of COVID-19 pandemic on clinical and nonclinical healthcare workers in India. Indian J Crit Care Med. 2021;25 (1):16-20. doi:10.5005/jp-journals-10071-23702

32. Agrawal S, Tandon V, Srivastava RM, Kaur ACOVID-19. pandemic - testing times for postgraduate medical education. Indian J Ophthalmol. 2021;69(1):157-158. doi:10.4103/ijo.IJO_3174_20

33. McCarthy C, Carayannopoulos K, Walton JM. COVID-19 and changes to postgraduate medical education in Canada. Can Med Assoc J. 2020;192(35):E1018-20. doi:10.1503/cmaj.200882

34. Sneyd JR, Mathoulin SE, O'Sullivan EP, et al. impact of the COVID-19 pandemic on anaesthesia trainees and their training. $\mathrm{Br}$ $J$ Anaesth. 2020;125(4):450-455. doi:10.1016/j.bja.2020.07.011

35. Sam AH, Millar KR, Lupton MGF. Digital clinical placement for medical students in response to COVID-19. Acad Med. 2020;95(8):1126

36. Alsoufi A, Alsuyihili A, Msherghi A, et al. Impact the COVID-19 pandemic on medical education: medical students' knowledge, attitudes, and practices regarding electronic learning. PLoS One. 2020;15(11):e0242905. doi:10.1371/journal.pone.0242905

37. Hollander JE, Carr BG. Virtually Perfect? Telemedicine for Covid-19. N Engl J Med. 2020;382(18):1679-1681. (). doi:10.1056/ NEJMp2003539

38. Dong C, Goh P. Twelve tips for the effective use of videos in medical education. Med Teach. 2015;37(2):140-145. doi:10.3109/ 0142159X.2014.943709

39. Hafferty FW, Franks R. The hidden curriculum, ethics teaching, and the structure of medical education. Acad Med. 1994;69(11):861-871. doi:10.1097/00001888-199411000-00001

40. Hafferty FW. Beyond curriculum reform: confronting medicine's hidden curriculum. Acad Med. 1998;73(4):403-407. doi:10.1097/ 00001888-199804000-00013

41. Karnieli-Miller O, Vu TR, Holtman MC, Clyman SG, Inui TS. Medical students' professionalism narratives: a window on the informal and hidden curriculum. Acad Med. 2010;85(1):124-133. doi:10.1097/ACM.0b013e3181c42896 
42. Gaufberg EH, Batalden M, Sands R, Bell SK. The hidden curriculum: what can we learn from third-year medical student narrative reflections? Acad Med. 2010;85(11):1709-1716. doi:10.1097/ ACM.0b013e3181f57899

43. Burford B. Group processes in medical education: learning from social identity theory. Med Educ. 2012;46(2):143-152. doi:10.1111/ j.1365-2923.2011.04099.x

44. Goldie J. The formation of professional identity in medical students: considerations for educators. Med Teach. 2012;34(9):e641-e648. doi:10.3109/0142159X.2012.687476

45. Jarvis-Selinger S, Pratt DD, Regehr G. Competency is not enough: integrating identity formation into the medical education discourse. Acad Med. 2012;87(9):1185-1190. doi:10.1097/ACM.0b013e3182604968
46. Lawrence C, Mhlaba T, Stewart KA, Moletsane R, Gaede B, Moshabela M. The hidden curricula of medical education: a scoping review. Acad Med. 2017;93(4):648. doi:10.1097/ ACM.0000000000002004

47. Liang ZC, Ooi SBS, Wang W. Pandemics and their impact on medical training: lessons from singapore. Acad Med. 2020;95 (9):1359-1361. (). doi:10.1097/ACM.0000000000003441

48. Gill D, Whitehead C, Wondimagegn D. Challenges to medical education at a time of physical distancing. Lancet. 2020;396 (10244):77-79. doi:10.1016/S0140-6736(20)31368-4

\section{Publish your work in this journal}

Advances in Medical Education and Practice is an international, peerreviewed, open access journal that aims to present and publish research on Medical Education covering medical, dental, nursing and allied health care professional education. The journal covers undergraduate education, postgraduate training and continuing medical education including emerging trends and innovative models linking education, research, and health care services. The manuscript management system is completely online and includes a very quick and fair peer-review system. Visit http://www.dovepress.com/testimonials.php to read real quotes from published authors. 